\title{
Hydroxyl-functionalized amphiphilic triblock copolyesters made of tartaric and lactic acids: Synthesis and nanoparticle formation
}

\author{
Elena Zakharova, ${ }^{1}$ Antxon Martínez de Ilarduya, ${ }^{1}$ Salvador León ${ }^{2}$ \\ and Sebastián Muñoz-Guerra ${ }^{1}$ \\ ${ }^{1}$ Departament d'Enginyeria Química, Universitat Politècnica de Catalunya, ETSEIB, Diagonal 647, \\ 08028 Barcelona, Spain \\ ${ }^{2}$ Departamento de Ingeniería Química, Universidad Politécnica de Madrid, ETSIIM, Gutiérrez \\ Abascal 2, 28006 Madrid, Spain
}

Corresponding author: sebastian.munoz@upc.edu

\begin{abstract}
Bio-based triblock copolyesters were synthesized by ring-opening polymerization of Llactide in solution using a hydroxyl-ended polytartrate as di-functional macroinitiator. This telechelic polyester with a $M_{\mathrm{n}}$ about $3000 \mathrm{~g} \cdot \mathrm{mol}^{-1}$ was obtained by non-stoichiometric melt polycondensation of dimethyl 2,3-di-O-isopropylidene-L-tartrate and 1,4-butanediol. Two symmetrical triblock copolyesters with $M_{\mathrm{n}}$ in the $5,000-7,000 \mathrm{~g} \cdot \mathrm{mol}^{-1}$ range and differing in the length of the polylactide blocks were prepared. The protecting isopropylidene group was removed in trifluoracetic acid to generate amphiphilic triblock copolyesters bearing free hydroxyl groups in the central block. All copolyesters started to decompose approximately at $260-280^{\circ} \mathrm{C}$, were semicrystalline, and readily degraded by hydrolysis of the main chain under both acid and basic conditions. The acetalized copolyesters had a single $T_{\mathrm{g}}$, whereas free-hydroxyl bearing copolyesters showed two $T_{\mathrm{g}}$ indicative of blocks phase separation. All copolyesters were able to form nanoparticles with average diameters within the $\sim 200-450$ $\mathrm{nm}$ range. The influence of the block lengths and protection/deprotection of the hydroxyl groups on size and $\zeta$-potential of the nanoparticles was evaluated.
\end{abstract}




\section{Introduction}

An important goal in drug therapy is to ensure the availability of the drug at the site of action while minimizing its exposure to non-target sites. One of the current methods of incorporating targeting ligands on the surface of nanoparticles involves chemical conjugation of the ligand to pre-synthesized nanoparticles [1-3]. A wide variety of ligands have been attached to nanoparticles allowing them to be used in sensing of biomolecules $[4,5]$ and cells, [6,7] diagnosis of diseases, [8] and intracellular delivery [9].

Poly(lactic acid) (PLA) and its copolymers with glycolic acid have been widely used to develop nanoparticle systems as suitable carriers for drug delivery [10-12], and functionalization of PLA polymers and copolymers has been carried out in a number of cases to improve the loading and administration of different kinds of drugs. Thus, aminefunctionalized poly(lactic-co-glycolic acid) (PLGA-NH $\left.{ }_{2}\right)$ was developed for building nanoparticles for the delivery of phloretin [13]. In another remarkable case, a functionalized copolyester, poly(lactic-co-hydroxymethyl glycolic acid) was synthesized [14,15]. The controlled introduction of side hydroxyl group led to systems with tunable degradability and improved cell adhesion by proper adjustment of the crystallinity and/or hydrophilicity. Also a system consisting of polyvinyl alcohol grafted with PLA and functionalized with phosphate groups has been reported as an efficient carrier for biofunctional agents with improved cell response [16]. The system was also proved to be suitable for materials with tunable surface or bulk properties of relevance for tissue engineering applications.

The approach mostly used for building amphiphilic PLA derivatives able to selfassemble in nanoparticles is copolymerization involving the insertion of hydrophilic blocks such as poly(ethylene glycol), polypeptides, and others $[17,18]$. Most of these syntheses are performed by ROP of the lactide initiated by the ended-functionalized hydrophilic counterpart to create diblock or triblock copolymers $[19,20]$. Functionalization of these amphiphilic copolyesters is usually restricted to the chain-ends, and therefore active functions are present in low concentration. A noteworthy different case has been reported by Armes et al. [21], who described the synthesis of thiol-functionalized amphiphilic polylactide-methacrylic diblock copolymers by addition-fragmentation chain transfer (RAFT) 
polymerization. Although the choice for the synthesis of block copolymers of ABA-type is frequently motivated by synthetic reasons, a number of triblock PLA-based copolyesters designed to display outstanding properties have been collected in these last years [20]. When the two blocks are thermodynamically incompatible these systems are able to selfassemble at a nanometric scale adopting nanostructures that endow them with peculiar properties [22]. In this regard, we have recently described biodegradable triblock copolyesters prepared by ROP of L-lactide initiated by a telechelic D-glucose-based macroinitiator [23]. These copolyesters were able to form biphasic nanoparticles with average diameters of $\sim 100-130 \mathrm{~nm}$. However triblock copolymers bearing internal functionalization are not very common. In fact, the triblock PLA-based copolyesters with the central block made of either ricinolate units [24] or thioether-containing 11-undecanoate units [25], are illustrative examples of such systems. To our knowledge no PLA-based block copolyesters provided with internal hydroxyl functionalization has been synthesized so far.

In this paper we wish to report on triblock copolyesters made of L-tartaric and L-lactic acids. L-tartaric acid is the common name of (2S,3S)-2,3-dihydroxy succinic acid, a naturaloccurring aldaric acid that is widely available, relatively inexpensive, and that has been extensively used in the synthesis of polyamides [26-28], polyesters [29], polyesteramides $[30,31]$, and polycarbonates [32,33]. In this work dimethyl 2,3-di-O-isopropylidene-L-tartrate (iThxCOOMe) was polycondensated with 1,4-butanediol to obtain an $\mathrm{OH}-(\mathrm{PBiThx})_{\mathrm{x}}-\mathrm{OH}$ telechelic homopolyester. iThxCOOMe had been already explored by Jacob et al. for the synthesis of aliphatic copolyesters [34]. Isopropylidene acetalized tartaric acid derivatives in general are bio-based monomers with a great potential in the synthesis of hydroxyfunctionalized polycondensates because, after polymerization, the isopropylidene group may be readily removed by treatment with acids. $\mathrm{OH}-(\mathrm{PBiThx})_{\mathrm{x}}-\mathrm{OH}$ is then copolymerized with L-lactide to produce triblock ABA copolyesters with the tartrate units either acetalized or with the hydroxyl groups in the free form after previous deacetalization. The thermal properties of these triblock copolyesters as well as their ability to form nanoparticles are comparatively examined paying particular attention to the effect of the state of the tartrate 
units (protected or deprotected), and the length of the polylactide blocks on particle size and structure.

\section{Experimental part}

\subsection{Materials}

The reagents 1,4-butanediol (BD, 99\%), dibutyl tin oxide (DBTO, 98\%), 2,3-di-Oisopropylidene-L-tartrate (iThxCOOMe), (3S,6S)-3,6-dimethyl-1,4-dioxane-2,5-dione (Llactide, 98\%), and 1,5,7-triazabicyclo[4.4.0]dec-5-ene (TBD, 98\%) were purchased from Sigma-Aldrich. Solvents used for purification, synthesis and characterization were all of either technical or high-purity grade, purchased from Panreac and used as received.

\subsection{General methods}

${ }^{1} \mathrm{H}$ and ${ }^{13} \mathrm{C}$ NMR spectra were recorded on a Bruker AMX-300 spectrometer at 25.0 ${ }^{\circ} \mathrm{C}$ operating at 300.1 and $75.5 \mathrm{MHz}$, respectively. Samples of about 10 or $50 \mathrm{mg}$ of polyester dissolved in $1 \mathrm{~mL}$ of solvent were used for ${ }^{1} \mathrm{H}$ and ${ }^{13} \mathrm{C} N M R$, respectively, and they were internally referenced to tetramethylsilane (TMS). $\mathrm{CDCl}_{3}$ or $\mathrm{CDCl}_{3} / \mathrm{TFA}(50 / 50)$ was the solvent used for the protected and deprotected polyester, respectively. Sixty-four scans for ${ }^{1} \mathrm{H}$ and $1,000-10,000$ scans for ${ }^{13} \mathrm{C}$ with 32 and $64-\mathrm{K}$ data points with relaxation delays of 1 and $2 \mathrm{~s}$, respectively, were registered. Gel permeation chromatograms were acquired at $35.0^{\circ} \mathrm{C}$ using Waters equipment provided with a refraction-index detector. The samples were chromatographed using $0.05 \mathrm{M}$ sodium trifluoroacetate-hexafluoro isopropanol mixture (NaTFA-HFIP) as mobile phase trough a gel column $(300 \times 7.5 \mathrm{~mm})$ with a flow rate of $0.5 \mathrm{~mL} \cdot \mathrm{min}^{-1}$. Chromatograms were calibrated against poly(methyl methacrylate) monodisperse standards. Thermogravimetric analyses were performed on a Mettler Toledo TGA/DSC 1 thermobalance under a nitrogen flow of $20 \mathrm{~mL} \cdot \mathrm{min}^{-1}$ at a heating rate of $10^{\circ} \mathrm{C} \cdot \mathrm{min}^{-1}$ within a temperature range of 30 to $600^{\circ} \mathrm{C}$. Sample weights of about $10-$ $15 \mathrm{mg}$ were used in these experiments. The thermal behavior of polyesters was examined by DSC from 3 to $5 \mathrm{mg}$ samples using a Perkin Elmer DSC-8000 apparatus at heating/cooling rates of $10^{\circ} \mathrm{C} \cdot \mathrm{min}^{-1}$, and under a nitrogen flow of $20 \mathrm{~mL} \cdot \mathrm{min}^{-1}$. Indium and 
zinc were used as standards for temperature and enthalpy calibrations, respectively. Glasstransition temperatures were determined by the tangent method from melt-quenched polymer samples at a heating rate of $20^{\circ} \mathrm{C} \cdot \mathrm{min}^{-1}$. Scanning electron microscopy images were taken with a field-emission JOEL JSM-7001F instrument (JEOL, Japan) from platinum/palladium coated samples. Dynamic light scattering for determination of particle hydrodynamical size and $\zeta$-potential measurements were performed with the Brookhaven NanoBrook, particle/protein size and zeta potential analyzer (Brookhaven Instruments Corporation, USA), with particles suspended in deionized water at concentrations in the $0.6-0.7 \mathrm{~g} \cdot \mathrm{mL}^{-1}$ range.

\subsection{Synthesis of telechelic $\mathrm{OH}-(\mathrm{PBiThx})_{19-} \mathrm{OH}$ homopolyester}

The aliphatic telechelic homopolyester was synthesized by melt polycondensation of BD (0.03 mol, $2.40 \mathrm{~g})$ with 2,3-di-O-isopropylidene-L-tartrate $(0.02 \mathrm{~mol}, 4.47 \mathrm{~g})$ using $30 \%$ mole excess of diol respect to diester. The reactants were stirred to get a homogeneous mixture, and DBTO $(0.1 \mathrm{mmol}, 0.02 \mathrm{~g})(0.5$ mole- $\%$ respect to the total of monomers $)$ was added as catalyst. The transesterification step was performed at $100{ }^{\circ} \mathrm{C}$ under nitrogen flow for $16 \mathrm{~h}$, and then polycondensation proceeded for $6 \mathrm{~h}$ at $110^{\circ} \mathrm{C}$ under vacuum $(0.03-0.06$ mbar). The NMR data ascertaining the constitution and purity of this polyester are described below.

$\mathrm{OH}-(\mathrm{PBiThx})_{19} \mathrm{OH}$ homopolyester: ${ }^{1} \mathrm{H}$ NMR (300.1 MHz, $\left.\mathrm{CDCl}_{3}\right), \delta$ (ppm): 4.69 (s, 2H, $\mathrm{OCHCH}), 4.25\left(\mathrm{~s}, 4 \mathrm{H}, \mathrm{OCH}_{2} \mathrm{CH}_{2}\right), 1.76\left(\mathrm{~s}, 4 \mathrm{H}, \mathrm{OCH}_{2} \mathrm{CH}_{2}\right), 1.54\left(\mathrm{~s}, 6 \mathrm{H}, \mathrm{CH}_{3}\right){ }^{13} \mathrm{C} \mathrm{NMR}(75.5$ $\left.\mathrm{MHz}, \mathrm{CDCl}_{3}\right), \delta(\mathrm{ppm}): 169.5(\mathrm{CO}), 113.8,77.0,65.0,26.2,24.9$.

\subsection{Synthesis of triblock $P L L A_{y}-(P B i T h x)_{19}-P L L A_{y}$ copolyesters}

The telechelic homopolyester $\mathrm{OH}-(\mathrm{PBiThx})_{19} \mathrm{OH}(0.13 \mathrm{mmol}, 0.6 \mathrm{~g})$ was dissolved in a $1 \mathrm{M}$ solution of L-lactide $(4.92 \mathrm{mmol}, 0.71 \mathrm{~g} / 7.38 \mathrm{mmol}, 1.06 \mathrm{~g})$ in dichloromethane (4 $\mathrm{ml} / 5 \mathrm{ml})$, and then $5 \%$-mole of TBD $(0.24 \mathrm{mmol}, 0.03 \mathrm{~g} / 0.36 \mathrm{mmol}, 0.05 \mathrm{~g})$ relative to lactide was added. The solution was stirred for 5 min under nitrogen atmosphere and the reaction stoped by inactivating the catalyst by addition of benzoic acid $(0.49 \mathrm{mmol}, 0.06 \mathrm{~g} /$ $0.73 \mathrm{mmol}, 0.09 \mathrm{~g}$ ). The copolyesters were recovered by precipitation upon pooring the 
reaction solution in methanol $(150 \mathrm{~mL})$. The NMR data of the copolyesters are listed below. Two copolyesters PLLA $_{y}-(\operatorname{PBiThx})_{x}-$ PLLA $_{y}$ with $y / x$ ratios of approximately 2 and 3 were obtained by this procedure. ${ }^{1} \mathrm{H}$ and ${ }^{13} \mathrm{C}$ spectra of these triblock copolyesters are practically indistinguishable for the two examined compositions.

PLLA $A_{y}-(P B i T h x){ }_{19}-P L L A_{y}$ copolyesters: ${ }^{1} \mathrm{H}$ NMR (300.1 MHz, $\left.\mathrm{CDCl}_{3}\right), \delta(\mathrm{ppm}): 5.2(\mathrm{~m}, \mathrm{y} \cdot 2 \mathrm{H}$, $\left.\mathrm{OCHCH}_{3}\right), 4.69(\mathrm{~s}, \mathrm{x} \cdot 2 \mathrm{H}, \mathrm{OCHCH}), 4.25\left(\mathrm{~s}, \mathrm{x} \cdot 4 \mathrm{H}, \mathrm{OCH}_{2} \mathrm{CH}_{2}\right), 1.76\left(\mathrm{~s}, \mathrm{x} \cdot 4 \mathrm{H}, \mathrm{OCH}_{2} \mathrm{CH}_{2}\right)$, $1.58\left(\mathrm{~d}, \mathrm{y} \cdot 6 \mathrm{H}, \mathrm{OCHCH}_{3}\right), 1.54\left(\mathrm{~s}, \mathrm{x} \cdot 6 \mathrm{H}, \mathrm{CH}_{3}\right) \cdot{ }^{13} \mathrm{C} \mathrm{NMR}\left(75.5 \mathrm{MHz}, \mathrm{CDCl}_{3}\right), \delta(\mathrm{ppm}): 169.5$ (CO), 113.8, 77.0, 65.0, 26.2, 24.9.

\subsection{Removal of the isopropylidene group from $P L L A_{y}-(P B i T h x)_{19}-P L L A_{y}$ copolyesters}

Removal of the isopropylidene group from the di-O-isopropylidene-L-tartrate unit was accomplished by treatment of the acetalized copolyesters with trifluoroacetic acid (TFA). The PLLA ${ }_{y}-(P B i T h x){ }_{19}-P_{L L A}(0.09 \mathrm{mmol}, 0.5 \mathrm{~g} / 0.07 \mathrm{mmol}, 0.5 \mathrm{~g})$ copolyester was stirred in aqueous TFA $(3.75 \mathrm{ml})(4: 1 \mathrm{v} / \mathrm{v})$ for $30 \mathrm{~min}$ until complete solution. The reaction mixture was then poured into diethyl ether $(150 \mathrm{ml})$ to precipitate the copolyester with the hydroxyl groups in the free form. The polymer was finally dried under vacuum and stored in a desiccator until needed. ${ }^{1} \mathrm{H}$ and ${ }^{13} \mathrm{C}$ spectra of the hydroxylated triblock copolyesters are practically indistinguishable for the two examined compositions.

PLLA $A_{y}-(P B T h O H){ }_{19}-P L L A_{y}$ copolyesters: ${ }^{1} \mathrm{H}$ NMR (300.1 MHz, $\left.\mathrm{CDCl}_{3} / \mathrm{TFA}\right), \delta$ (ppm): 5.32 $\left(\mathrm{m}, \mathrm{y} \cdot 2 \mathrm{H}, \mathrm{OCHCH}_{3}\right), 4.91(\mathrm{~s}, \mathrm{x} \cdot 2 \mathrm{H}, \mathrm{COCHOH}), 4.39\left(\mathrm{~s}, \mathrm{x} \cdot 4 \mathrm{H}, \mathrm{OCH}_{2} \mathrm{CH}_{2}\right), 1.86(\mathrm{~s}, \mathrm{x} \cdot 4 \mathrm{H}$, $\mathrm{OCH}_{2} \mathrm{CH}_{2}$ ), 1.54 (s, $\left.6 \mathrm{H}, \mathrm{CH}_{3}\right){ }^{13} \mathrm{C}$ NMR (75.5 MHz, CDCl 3 TFA), $\delta$ (ppm): 169.5 (CO), $113.8,77.0,65.0,26.2,24.9$.

\subsection{Hydrolytic degradation}

Films for hydrolytic degradation and biodegradation studies were prepared with a thickness of $200 \mu \mathrm{m}$ by casting from chloroform solution with a polymer concentration of $100 \mathrm{~g} \cdot \mathrm{L}^{-1}$. The films were cut into $10 \mathrm{~mm}$ diameter, 20-30 mg weight disks, and dried under vacuum to constant weight. For hydrolytic degradation, samples were immersed in vials containing $10 \mathrm{~mL}$ of citric acid buffer ( $\mathrm{pH} 2.0)$, sodium phosphate buffer $(\mathrm{pH} 7.4)$, or sodium carbonate buffer $\left(\mathrm{pH} \mathrm{10)}\right.$ at $37^{\circ} \mathrm{C}$ for 40 days. Disks were withdrawn from the incubation 
medium at scheduled periods of time, washed carefully with distilled water, dried to constant weight, and analyzed by GPC chromatography and NMR spectroscopy. For the analysis of the products released to the incubation medium, a few $\mathrm{mg}$ of samples were immersed in NMR tubes containing $1 \mathrm{~mL}$ of $\mathrm{D}_{2} \mathrm{O}$ at the selected $\mathrm{pH}$, and ${ }^{1} \mathrm{H}$ NMR spectra recorded from the supernatant at scheduled times.

\subsection{Nanoparticle formation}

Nanoparticles of PLLA ${ }_{y}-(\mathrm{PBiThx})_{19}-\mathrm{PLLA}_{\mathrm{y}}$ and $\mathrm{PLLA}_{\mathrm{y}}-(\mathrm{PBThOH})_{19}-\mathrm{PLLA}_{\mathrm{y}}$ copolyesters were prepared by the precipitation-dialysis method. $2 \mathrm{mg}$ of the block copolyester were dissolved in $1 \mathrm{~mL}$ of DMSO and the same volume of water added to yield a translucent solution. This solution was dialyzed against distilled water for $72 \mathrm{~h}$ at room temperature using cellulose membrane tubes $\left(2000 \mathrm{~g} \cdot \mathrm{mol}^{-1}\right.$ molecular weight cut-off) with frequent replacement of the external medium. The particles generated upon dialysis were subjected to SEM examination and light-scattering measurements.

\subsection{Simulation studies}

The morphological properties at the molecular level of the copolyesters containing protected and non-protected tartrate units were comparatively studied by molecular dynamics (MD) simulations. A cubic periodic box consisting on 64 polymer chains of either PLLA $_{17}-(\text { PBiThx })_{17}-$ PLLA $_{17}$ or PLLA $_{17}-(\text { PBThOH })_{17}-$ PLLA $\left._{17}\right)$, was simulated in the NPT ensemble (number of moles, pressure and temperature constants) at room temperature. Average box dimensions were $8 \mathrm{~nm}$ and $8.4 \mathrm{~nm}$, respectively.

The General AMBER Force Field (GAFF) [35] was chosen to describe the potential energy. Atomic charge parameters were obtained by fitting to the molecular electrostatic potential. The electrostatic potential was computed at the B3LYP/6-31G* level for optimized geometries of the different repeating units. Ab-initio calculations were done with Q-Chem [36]. The generation of starting structures for MD proceeded in the following way: random configurations were generated with the PACKMOL program [37], taking the different polymer geometries that were obtained from a preliminary single-chain MD trajectory. The structure was then relaxed through an energy optimization and a NVT (ensembles with 
number of moles, volume and temperature constants) $1 \mathrm{~ns}$ MD at $300 \mathrm{~K}$. The system was then subjected to a simulated heating treatment consisting on a progressive increase of temperature up to $1000 \mathrm{~K}$ during $1 \mathrm{~ns}$ in the NPT ensemble followed with a $1000 \mathrm{~K} \mathrm{NPT}$ for $1 \mathrm{~ns}$, and a slow cooling down NPT to $300 \mathrm{~K}$ for $10 \mathrm{~ns}$. After equilibration, a production run of $5 \mathrm{~ns}$ in the NPT ensemble at $300 \mathrm{~K}$ was performed. All the MD simulations were carried out with Large-scale Atomic/Molecular Massively Parallel Simulator (LAMMPS) [38].

\section{Results and discussion}

\subsection{Synthesis and chemical structure}

The synthetic route followed in this work to obtain the triblock copolyesters is depicted in Scheme 1. The $\mathrm{OH}-(\mathrm{PBiThx})_{19}-\mathrm{OH}$ telechelic homopolyester was synthesized by a twosteps polymerization reaction in the melt from 1,4-butanediol and 2,3-di-O-isopropylidene-Ltartrate using DBTO as catalyst. An excess of $30 \%$-mole of diol was used in order to generate hydroxyl-capped oligoesters containing around twenty repeating units. The first step was carried out at $100^{\circ} \mathrm{C}$ under a nitrogen flow to sweep off the methanol generated by transesterification. The second step was carried out at $110^{\circ} \mathrm{C}$ under vacuum to remove exhaustively the small amounts of remaining methanol. ${ }^{1} \mathrm{H}$ and ${ }^{13} \mathrm{C}$ spectra of $\mathrm{OH}$ $(\mathrm{PBiThx})_{19}-\mathrm{OH}$ homopolyester with indication of all signals assignments are accessible in

Figure $\mathrm{S} 1$ of the Supporting Information file $(\mathrm{SI})$ linked to this paper. These spectra ascertained the chemical constitution expected for this telechelic homopolyester. A comparative quantification of the proton resonance signals arising from inner and ending $\mathrm{BD}$ units was used to estimate its number average polymerization degree which resulted to be around 19 .

Triblock copolyesters PLLA ${ }_{y}-(P B i T h x){ }_{19}-P L L A_{y}$ were successfully synthesized by ROP of L-lactide (LLA) in the presence of $\mathrm{OH}-(\mathrm{PBiThx})_{19}-\mathrm{OH}$ which operated as a di-functional macroinitiator. The reaction was finished by lowering the temperature and adding benzoic acid to inactivate the catalyst. By this means, undesirable transesterifications taking place during subsequent handling of the reaction mixture, which are known to promote randomization [23], could be prevented. The amounts of lactide and $\mathrm{OH}-(\mathrm{PBiThx})_{19}-\mathrm{OH}$ 
made to react were accurately adjusted to target copolyesters with selected LLA/BiThx ratios of 4 and 6 , i.e. with theoretical $x$ values of 38 and 57 , respectively. The chemical constitution and composition of the two triblock copolyesters was definitely ascertained by NMR. The ${ }^{1} \mathrm{H}$ and ${ }^{13} \mathrm{C}$ NMR spectra of PLLA ${ }_{38}-(\mathrm{PBiThx}){ }_{19}-\mathrm{PLLA}_{38}$ copolyester are depicted in Figure 1 for illustrating purposes, and those recorded for the PLLA ${ }_{57}-(\mathrm{PBiThx})_{19}-\mathrm{PLLA} \mathrm{A}_{57}$ homologue are included in the SI file (Figure S2). All signals could be straightforwardly assigned and no significant peaks revealing the presence of impurities were present in these spectra. Copolyester compositions were determined by integration of the proton signals arising specifically from the two block units. The obtained values were fairly close to those used in the respective feeds, which led to conclude that L-lactide must have reacted almost completely by ROP. The characteristic peaks at $3.7 \mathrm{ppm}$ corresponding to $-\mathrm{CH}_{2} \mathrm{OH}$ end groups disappeared as conversion of $\mathrm{OH}-(\mathrm{PBiThx}){ }_{19}-\mathrm{OH}$ increased confirming the formation of the ester functions upon reaction with the lactide.

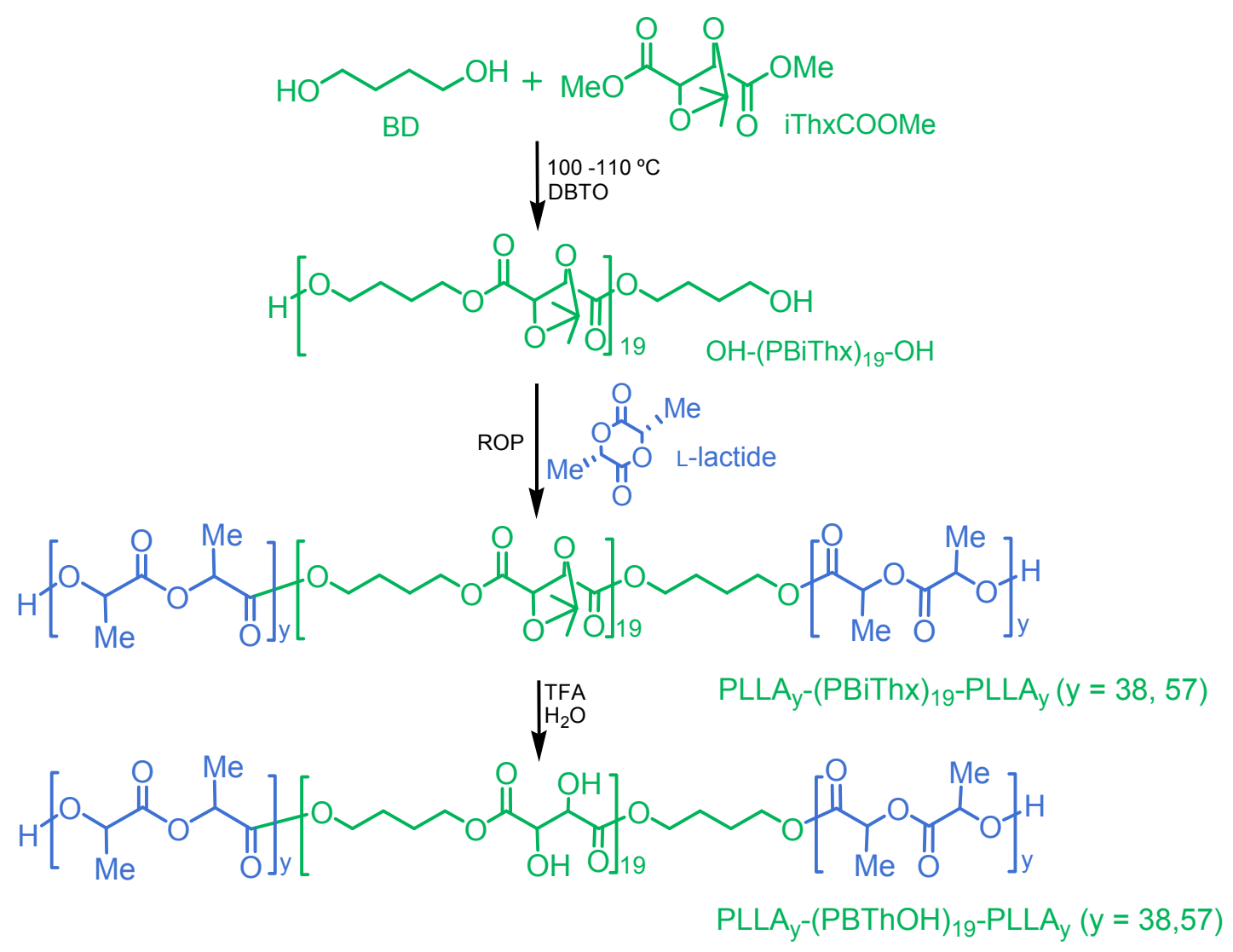

Scheme 1. Synthesis route leading to triblock PLLA $_{y}-(P B T h O H){ }_{19}-P-A_{y}$ copolyesters. 
Removal of isopropylidene groups of the acetalized tartrate units present in PLLA ${ }^{-}$ (PBiThx $)_{x}-$ PLLA $A_{y}$ copolyesters was accomplished by treatment with aqueous trifluoroacetic acid for $5 \mathrm{~min}$. After deprotection the copolyesters became soluble in water and DMSO. The GPC analysis of deprotected PLLA ${ }_{38}-(\mathrm{PBThOH})_{19}-\mathrm{PLLA}_{38}$ and PLLA ${ }_{57}-(\mathrm{PBThOH})_{19}-\mathrm{PLLA} \mathrm{A}_{57}$ copolyesters showed $M_{\mathrm{n}}$ of 4,600 and $6,800 \mathrm{~g} \cdot \mathrm{mol}^{-1}$ respectively, which are values close to those of their precursors. GPC curves of both protected and deprotected copolyesters are provided in Figure $\mathrm{S} 3$ of the $\mathrm{SI}$ file The two $\mathrm{PLLA}_{\mathrm{x}}-(\mathrm{PBThOH})_{19}-\mathrm{PLLA} \mathrm{A}_{\mathrm{x}}$ copolyesters were also characterized by NMR spectroscopy as illustrated in Figure 2 and Figure S4, respectively. Compared to the acetalized copolyesters, the free-hydroxyl containing copolyesters were found to be slightly enriched in tartrate units, which may be explained by the incidental occurrence of hydrolysis of the PLLA blocks taking place during the treatment with aqueous TFA. In agreement with such interpretation, deacetalization of the HO(PBiThx $)_{19}-\mathrm{OH}$ was found to led to $\mathrm{HO}-(\mathrm{PBThOH})_{19}-\mathrm{OH}$ with exactly the expected molecular weight. Composition and molecular weight data collected for the telechelic homopolyester and the triblock copolyesters are given in Table 1.

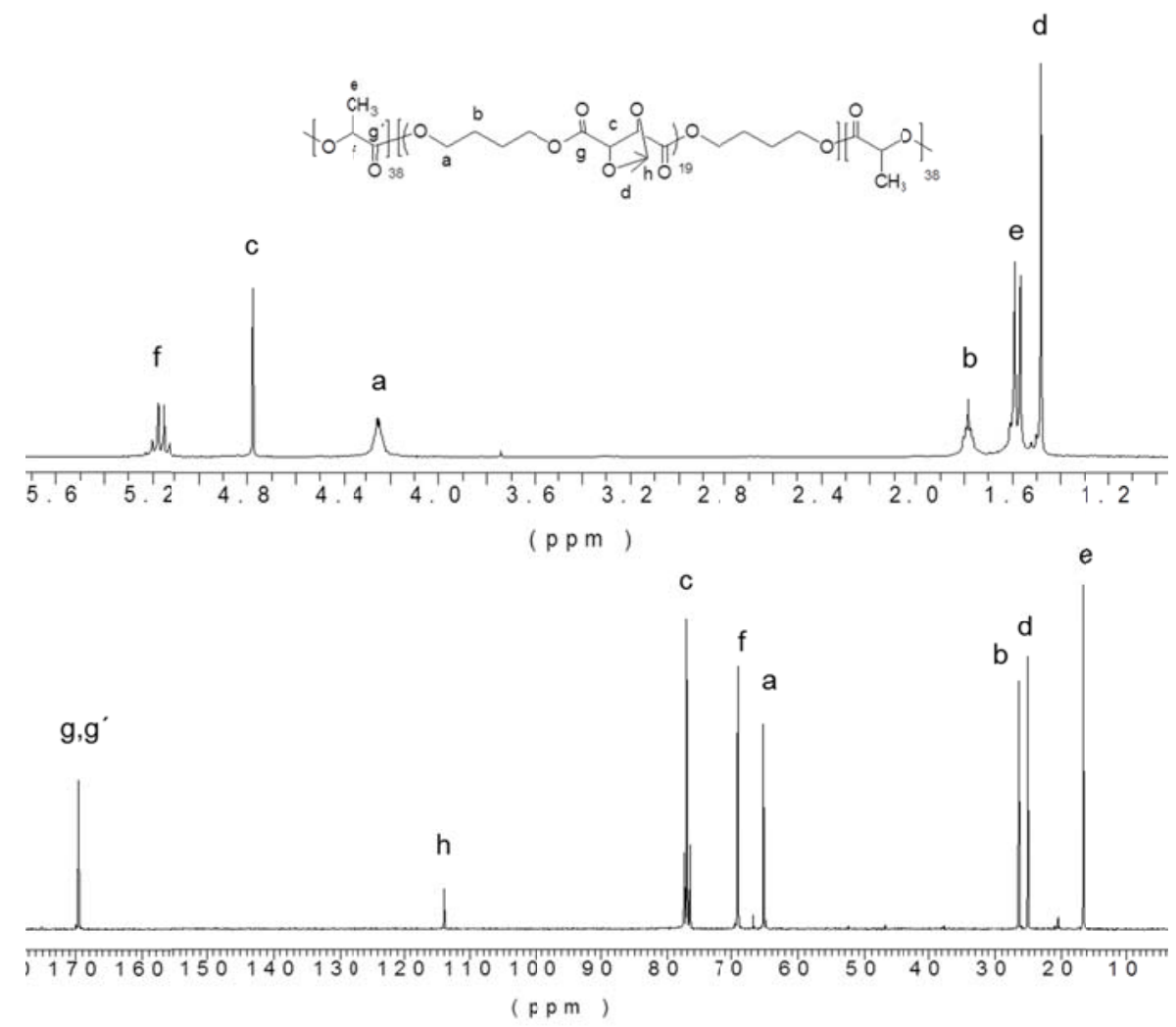

Figure 1. ${ }^{1} \mathrm{H}$ (top) and ${ }^{13} \mathrm{C}$ NMR spectra (bottom) of $\mathrm{PLLA}_{38}-(\mathrm{PBiThx}){ }_{19}-\mathrm{PLLA}_{38}$ triblock copolyester. 
Table 1. Composition and molecular weights of telechelic homopolyesters and triblock copolyesters.

\begin{tabular}{|c|c|c|c|c|c|}
\hline \multirow[t]{2}{*}{ Polyester } & \multicolumn{2}{|c|}{$\begin{array}{l}\text { Composition }{ }^{a} \\
(\mathrm{~mol} / \mathrm{mol})\end{array}$} & \multicolumn{3}{|c|}{$\begin{array}{l}\text { Molecular weight } \\
\left(\mathrm{g} \cdot \mathrm{mol}^{-1}\right)\end{array}$} \\
\hline & Feed & Copolyester & $M_{\mathrm{n}}$ & $M_{\mathrm{w}}$ & $\theta$ \\
\hline$\overline{\mathrm{OH}-(\mathrm{PBiThx})_{19}-\mathrm{OH}}$ & $100 / 0$ & $100 / 0$ & 3100 & 6600 & 2.1 \\
\hline $\mathrm{PLLA}_{38}-(\mathrm{PBiThx})_{19}-\mathrm{PLLA}_{38}$ & $20.0 / 80.0$ & $20.5 / 79.5$ & 5300 & 12400 & 2.3 \\
\hline PLLA $_{57}-(\mathrm{PBiThx})_{19}-\mathrm{PLLA}_{57}$ & $14.3 / 85.8$ & $15.4 / 84.6$ & 7000 & 12400 & 1.8 \\
\hline $\mathrm{OH}-(\mathrm{PBThOH})_{19}-\mathrm{OH}$ & $100 / 0$ & $100 / 0$ & 2500 & 4500 & 1.8 \\
\hline $\mathrm{PLLA}_{38^{-}}(\mathrm{PBThOH})_{19^{-}}-\mathrm{PLLA}_{38}$ & $20.0 / 80.0$ & $21.4 / 78.6$ & 4600 & 7800 & 1.7 \\
\hline $\mathrm{PLLA}_{57}-(\mathrm{PBThOH})_{19}-\mathrm{PLLA}_{57}$ & $14.3 / 85.7$ & $17.5 / 82.5$ & 6800 & 11800 & 1.7 \\
\hline
\end{tabular}

${ }^{a}$ Molar ratio (iBThx or BThOH to LLA) in the feed or in the copolymer, the latter determined by integration of ${ }^{1} \mathrm{H}$ NMR spectra.

${ }^{\mathrm{b}}$ Determined by GPC in HFIP against PMMA standards.

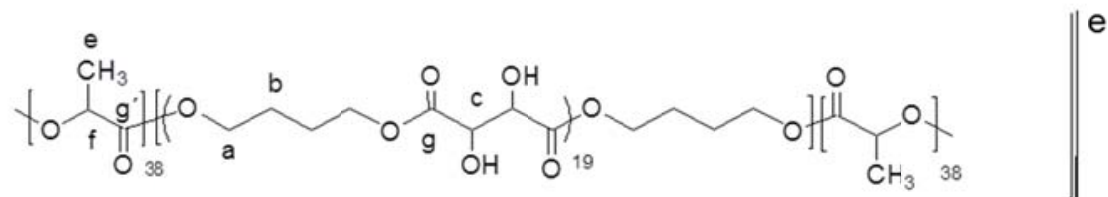
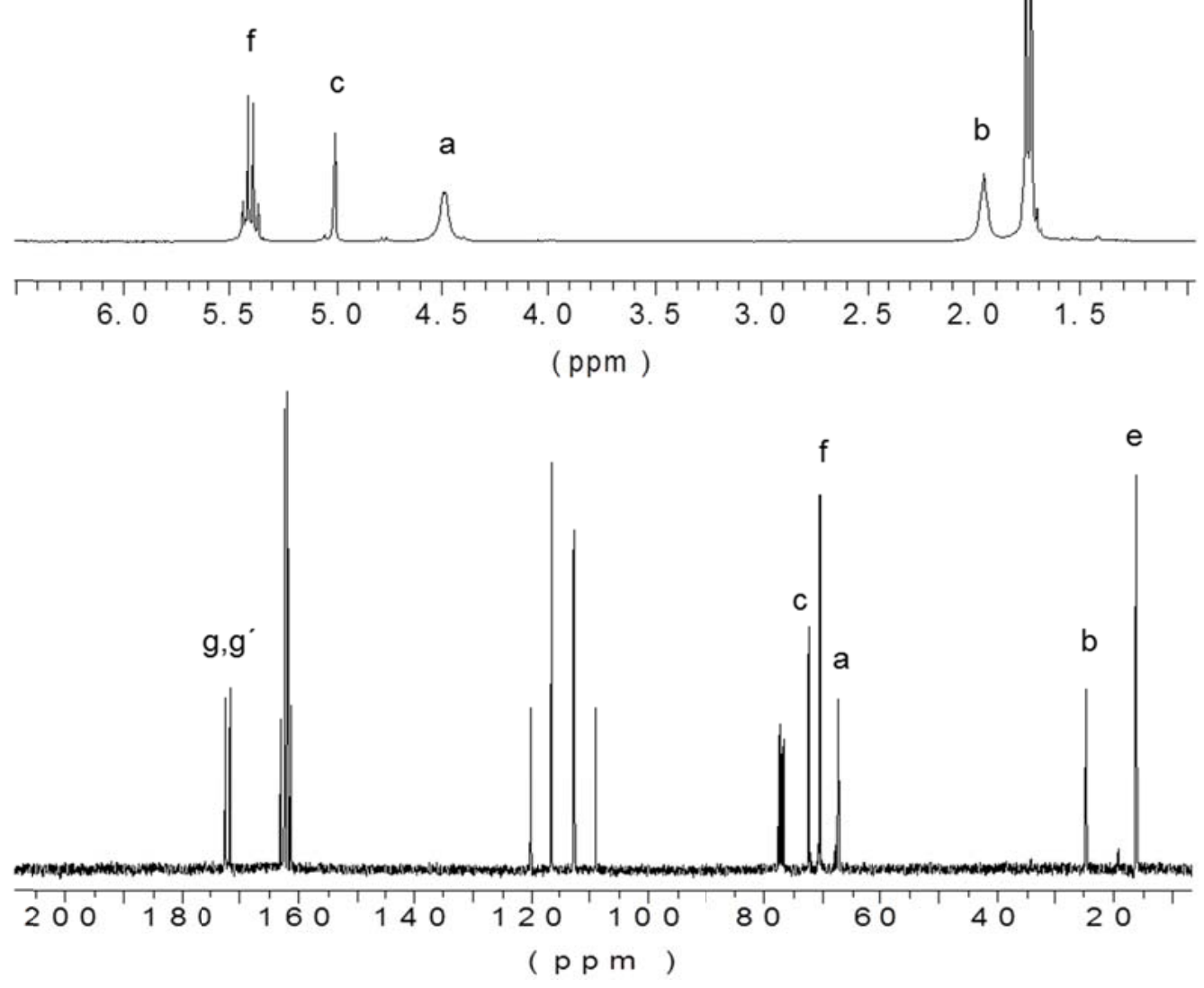

Figure 2. ${ }^{1} \mathrm{H}$ (top) and ${ }^{13} \mathrm{C}$ NMR spectra (bottom) of $\mathrm{PLLA}_{38}-(\mathrm{PBThOH}){ }_{19}-\mathrm{PLLA}_{38}$ triblock copolyester. 


\subsection{Thermal properties}

The thermal behaviour of the telechelic homopolyesters and the two triblock copolyester pairs prepared in this work has been examined by thermal gravimetric analysis (TGA) and differential scanning calorimetry (DSC). The most significant thermal data supplied by these assays are collected in Table 2 .

The thermal stability was measured in the range of $30-600{ }^{\circ} \mathrm{C}$ range under a nitrogen flow, and the registered TGA traces are compared in Figure 3. As can be seen, the acetalized telechelic homopolyester started to decompose approximately at $300{ }^{\circ} \mathrm{C}$ displaying an unique degradation step that proceeded with maximum rate at a temperature close to $350{ }^{\circ} \mathrm{C}$, while the deprotected one began to degrade at much lower temperature $\left(\sim 250{ }^{\circ} \mathrm{C}\right)$ with a maximum rate of decomposition at $300{ }^{\circ} \mathrm{C}$. The acetalized triblock copolyesters started to decompose at $30-40^{\circ} \mathrm{C}$ below the temperature of decomposition of the telechelic homopolyester, while the opposite effect was observed for the deprotected polyesters pair. Another noteworthy difference is that the acetalized copolyesters decomposed through at least two degradation steps, while the deprotected ones did it in only one step.

Main peaks corresponding to temperatures of maximum degradation rates were observed on the derivatives curves of the TGA traces in the $\sim 300-360^{\circ} \mathrm{C}$ range. In the case of acetalized copolyesters, the weight loss taking place at the lower temperature step (305$310^{\circ} \mathrm{C}$ ) was found to nearly correspond to the complete disappearance of the PLLA blocks whereas that measured for the higher temperature one $\left(345-347^{\circ} \mathrm{C}\right)$ was not far from that expected for the decomposition of the PBiThx block. Remaining weight after heating at 600 ${ }^{\circ} \mathrm{C}$ was $6-8 \%$ the highest for the telechelic homopolyesters whereas values within the $3-5 \%$ range were observed for the copolyesters. These TGA results lead to conclude that these compounds are heat resistant enough as to be comfortably handled by thermal processing. 
Table 2. Thermal properties of telechelic homopolyester and triblock copolyesters.

\begin{tabular}{|c|c|c|c|c|c|c|c|c|c|c|c|c|}
\hline \multirow[t]{3}{*}{ Polyester } & \multirow{2}{*}{\multicolumn{3}{|c|}{$\mathrm{TGA}^{\mathrm{a}}$}} & \multicolumn{9}{|c|}{$\mathrm{DSC}^{\mathrm{b}}$} \\
\hline & & & & \multicolumn{3}{|c|}{ First heating } & \multicolumn{2}{|c|}{ Cooling } & \multicolumn{4}{|c|}{ Second heating } \\
\hline & $\begin{array}{c}{ }^{\circ} T_{\mathrm{d}} \\
\left({ }^{\circ} \mathrm{C}\right)\end{array}$ & $\begin{array}{c}\max ^{\max } T_{\mathrm{d}} \\
\left({ }^{\circ} \mathrm{C}\right)\end{array}$ & $\begin{array}{l}\text { RW } \\
(\%)\end{array}$ & $\begin{array}{c}T_{\mathrm{g}} \\
\left({ }^{\circ} \mathrm{C}\right)\end{array}$ & $\begin{array}{c}T_{\mathrm{m}} \\
\left({ }^{\circ} \mathrm{C}\right)\end{array}$ & $\frac{\Delta H_{\mathrm{m}}}{\left(\mathrm{J} \cdot \mathrm{g}^{-1}\right)}$ & $\begin{array}{c}T_{\mathrm{c}} \\
\left({ }^{\circ} \mathrm{C}\right)\end{array}$ & $\begin{array}{l}\Delta H_{\mathrm{c}} \\
\left(\mathrm{J} \cdot \mathrm{g}^{-}\right.\end{array}$ & $\begin{array}{c}T_{\mathrm{cc}} \\
\left({ }^{\circ} \mathrm{C}\right)\end{array}$ & $\begin{array}{c}\Delta H_{\mathrm{cc}} \\
\left(\mathrm{J} \cdot \mathrm{g}^{-1}\right)\end{array}$ & $\begin{array}{c}T_{m} \\
\left({ }^{\circ} \mathrm{C}\right)\end{array}$ & $\begin{array}{c}\Delta H_{\mathrm{m}} \\
\left(\mathrm{J} \cdot \mathrm{g}^{-1}\right)\end{array}$ \\
\hline $\mathrm{OH}-(\mathrm{PBiThx})_{19}-\mathrm{OH}$ & 297 & 346 & 8 & -5 & - & - & - & - & - & - & - & - \\
\hline $\mathrm{PLLA}_{38^{-}}(\mathrm{PBiThx})_{19}-\mathrm{PLLA}_{38}$ & 258 & $310 / 347 / 359$ & 4 & 24 & 137 & 24.6 & - & - & 100.6 & -9.0 & $124 / 137$ & 17.8 \\
\hline PLLA $\left._{57-(P B i T h x}\right)_{19}-$ PLLA $_{57}$ & 263 & $307 / 344 / 359$ & 4 & 30 & 154 & 36.7 & 80 & 16.0 & - & - & 153 & 25.7 \\
\hline $\mathrm{OH}-(\mathrm{PBThOH})_{19}-\mathrm{OH}$ & 253 & 309 & 6 & 28 & 148 & 62.9 & - & - & 96 & -36.7 & 146 & 57.5 \\
\hline $\mathrm{PLLA}_{38}-(\mathrm{PBThOH}){ }_{19}-\mathrm{PLLA}_{38}$ & 260 & 304 & 5 & $35 / 48$ & 147 & 39.7 & - & - & 107 & -23.6 & $131 / 143$ & 25.6 \\
\hline PLLA $_{57^{-}}(\mathrm{PBThOH}){ }_{19}-\mathrm{PLLA}_{57}$ & 276 & 318 & 3 & $29 / 47$ & 147 & 45.9 & - & - & 98 & -26.3 & 145 & 37.1 \\
\hline
\end{tabular}

${ }^{a}$ Onset decomposition temperature corresponding to $5 \%$ of weight loss $\left({ }^{\circ} T_{\mathrm{d}}\right)$, temperature of maximum degradation rate $\left({ }^{\max } T_{\mathrm{d}}\right)$ and $\%$ of weight remaining after heating at $600^{\circ} \mathrm{C}(\mathrm{RW})$.

${ }^{b}$ Glass-transition temperature $\left(T_{\mathrm{g}}\right)$ taken as the inflection point of the heating DSC traces of melt-quenched samples recorded at $20{ }^{\circ} \mathrm{C} \cdot \mathrm{min}^{-1}$. Melting and crystallization temperatures $\left(T_{\mathrm{m}}, T_{c}\right)$ and their respective enthalpies $\left(\Delta H_{\mathrm{m}}, \Delta H_{\mathrm{c}}\right)$ measured at heating/cooling rates of $10^{\circ} \mathrm{C} \cdot \mathrm{min}^{-1}$ of powdered samples coming directly from synthesis. $T_{c c}$ and $\Delta H_{c c}$ refer to cold crystallization temperature and enthalpy, respectively. 

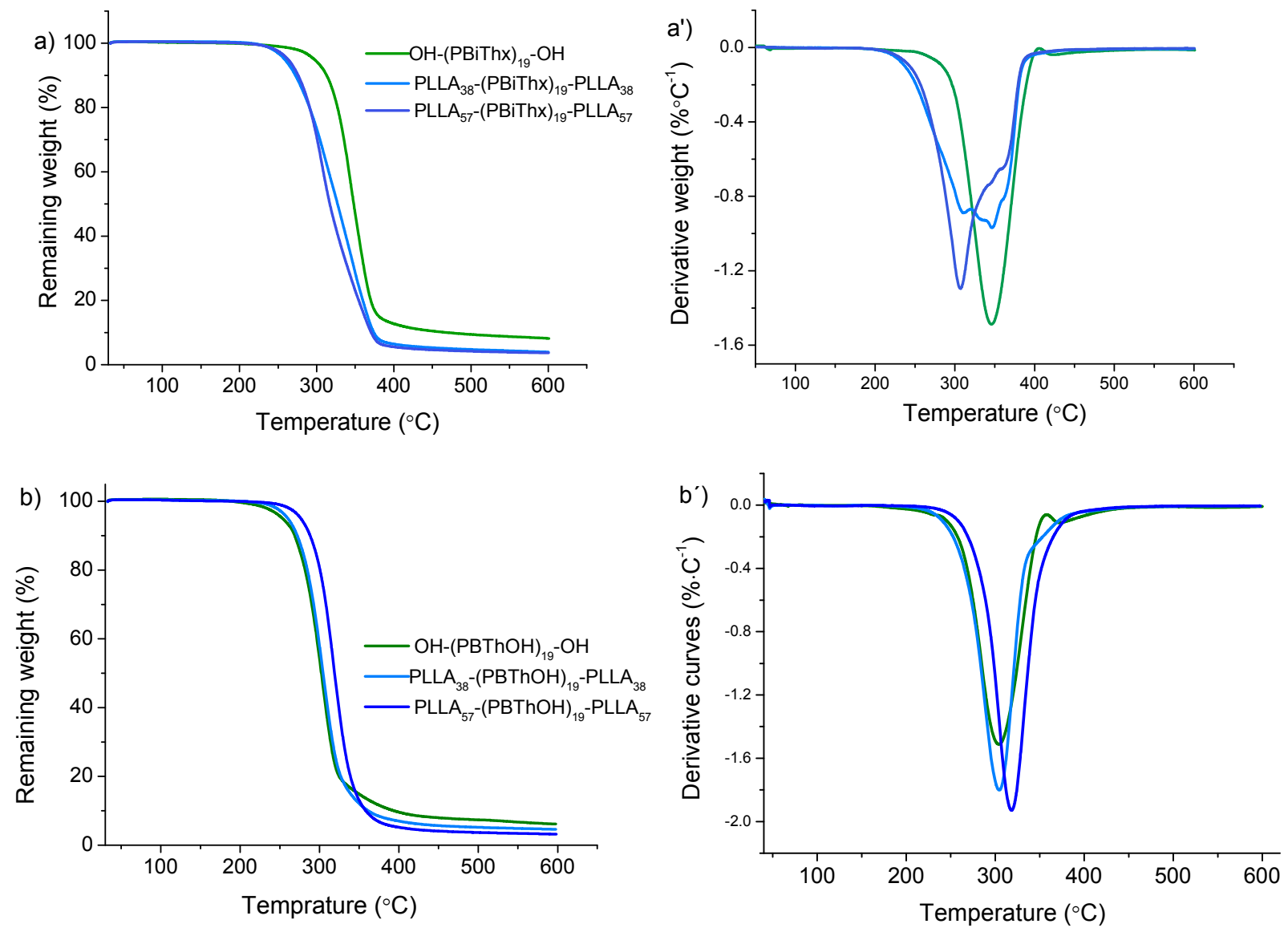

Figure 3. TGA traces of polyesters and their derivative curves.

A DSC analysis was carried out in order to appraise the behavior of the synthesized polyesters regarding reversible thermal transitions. The DSC traces of triblock copolyesters are represented in Figure 4 whereas those recorded from the two telechelic homopolyesters (protected and deprotected) are accessible in the SI file (Figure S5). The two acetalized copolyesters were found to be semicrystalline showing a melting peak from the lactide blocks at temperatures of $137^{\circ} \mathrm{C}$ and $154^{\circ} \mathrm{C}$ for their shorter and longer lengths, respectively. The deacetalized copolyesters showed a melting endotherm at $147^{\circ} \mathrm{C}$ which is interpreted as the overlapped melting peaks of PBThOH and PLLA blocks. The split of such endotherm into two peaks seen on the traces recorded from samples crystallized from the melt shold be due therefore to the separate melting of the two blocks. 

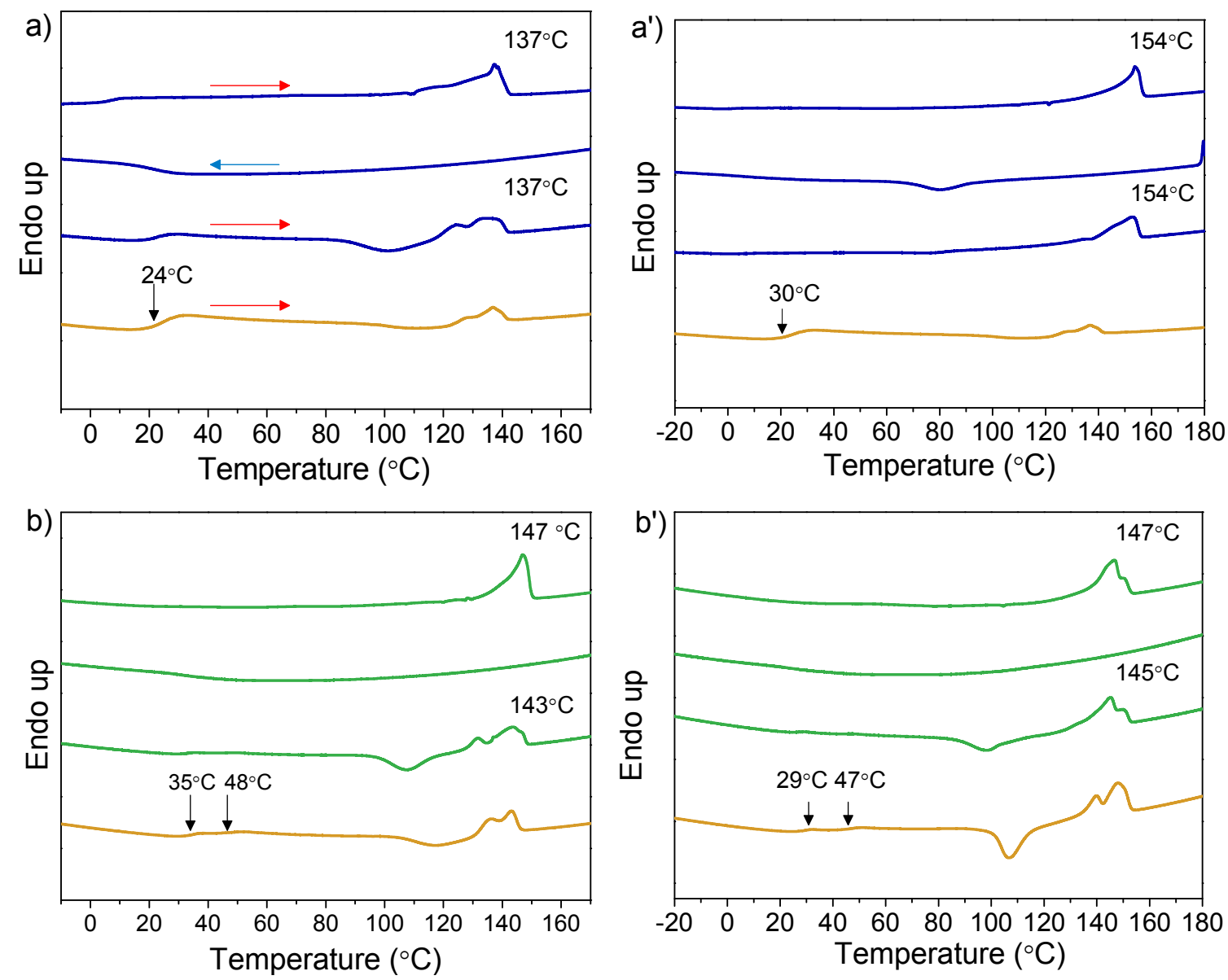

Figure 4. DSC traces of triblock copolyesters registered at successive heating and cooling as arrows

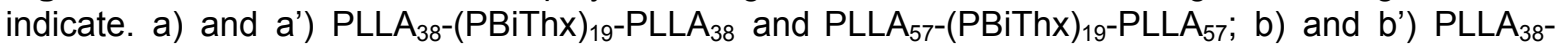
$(\mathrm{PBThOH})_{19}-\mathrm{PLLA}_{38}$ and PLLA ${ }_{57}-(\mathrm{PBThOH})_{19}-\mathrm{PLLA}_{57}$. The bottom traces (in orange) were registered from samples that were quenched from the melt.

The glass-transition temperatures of the polyesters were estimated by DSC from samples that were quenched from the melt. The $T_{\mathrm{g}}$ values measured on the heating traces are indicated in Figure 4 (orange traces), and enlarged selected areas allowing a clearer visualization of the characteristic inflections are provided in Figure S5 of the SI file for the two PLLA $A_{y}-(\mathrm{PBThOH})_{19}-\mathrm{PLLA}_{\mathrm{y}}$ copolyesters. The telechelic $\mathrm{OH}-(\mathrm{PBiThx})_{19}-\mathrm{OH}$ homopolyester displayed a $T_{\mathrm{g}}$ of $-5^{\circ} \mathrm{C}$ which is close to the value of $-3^{\circ} \mathrm{C}$ reported for the $T_{\mathrm{g}}$ of the PBThx polyester made from dimethyl 2,3-di-O-methylene-L-tartaric acid and BD [39]. The PLLA ${ }_{38}-(\mathrm{PBiThx})_{19}-\mathrm{PLLA}_{38}$ and $\mathrm{PLLA}_{57}-(\mathrm{PBiThx})_{19}-\mathrm{PLLA}_{57}$, triblock copolyesters showed only one $T_{\mathrm{g}}$ at 24 and $33^{\circ} \mathrm{C}$, respectively. These single $T_{\mathrm{g}}$ 's are intermediate between those of $\mathrm{OH}-(\mathrm{PBiThx})_{19}-\mathrm{OH}$ and PLLA, and their relative values are consistent with the length of the PLLA blocks present in each copolyester. Such behavior is taken as a 
solid indication of the miscibility of PBiThx and PLLA blocks. Conversely, the hydroxylated copolyesters displayed two $T_{\mathrm{g}}$ 's, with the lower one corresponding to the glass-transition of the tartaric derived block and the higher one corresponding to the PLLA block. It can be inferred from this result that two phases are present in these hydroxylated copolyesters as it should be expected from the large constitutional differences between the blocks. In fact, the PBThOH block has a pronounced hydrophilic character availed by the presence of two hydroxyl groups in the repeating unit whereas the PLLA block is essentially hydrophobic.

\subsection{Simulation studies}

In order to support theoretically the differences in phase behavior displayed by the acetal protected and hydroxyl-containing triblock copolyesters, an exploratory molecular dynamics simulation study (MD) was performed. Figure 5 displays the snapshots of the structure of two triblock systems with similar block composition and lengths but differing in that the tartrate units are acetalized or not. The difference between the BTh and LLA blocks becomes reflected in the resulting morphology, in which lactate units (b/ue) and butylene tartrate units (green) appear aggregated in separate regions. According to expectations and in agreement with the results afforded by DSC the mutual segregation of the two blocks is more conspicuous in the case of the hydroxylated copolyesters.
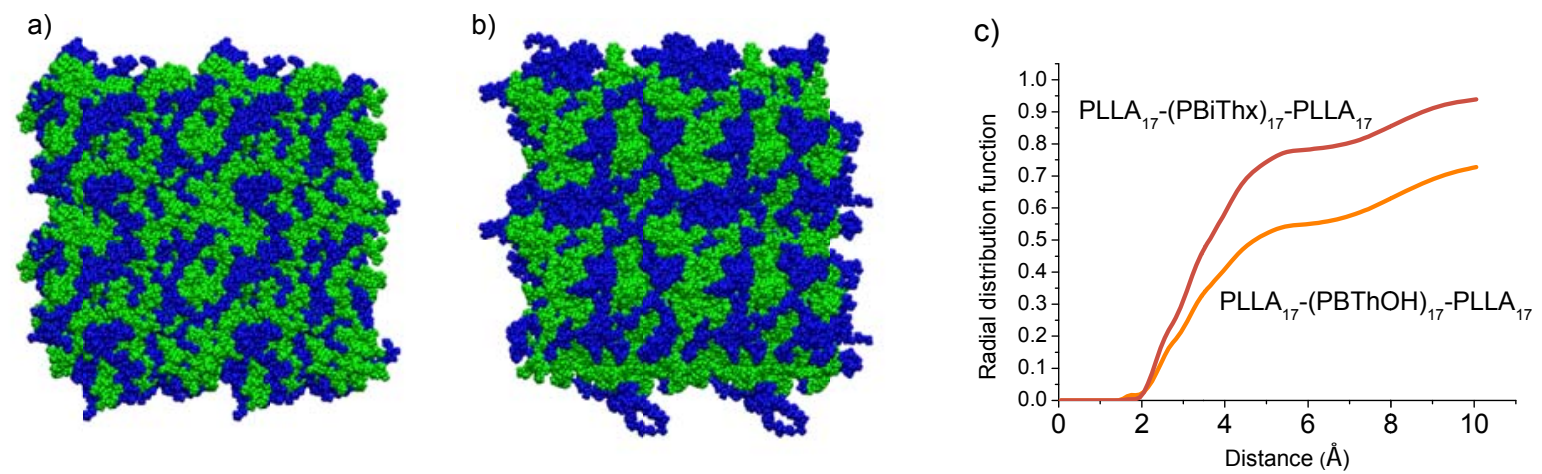

Figure 5. MD snapshots for the model copolyesters with protected (a) and non-protected (b) tartrate units. Lactate blocks are depicted in blue color and butylene tartrate blocks in green. Four periodic boxes are displayed (see details of the applied methodology in the Experimental section). c) Radial distribution function between the lactate repeat units and the butylene tartrate units for the two compared copolyesters (c). 
The relative localization of the different units in the copolymer can be described in terms of the radial distribution function. This function is defined as the population of pairs of units that are separated by a given distance and it provides information about the tendency of the different units to be close to each other. Figure $5 c$ displays a comparison of the radial distribution function between lactate units and butylene tartrate units for the two simulated systems. The profiles show that the proportion of pairs at short distances in the copolymer bearing free hydroxyl groups is significantly smaller than for the copolyesters having the tartrate units modified by acetalization. This result confirms that the interaction between LLA and BTh blocks must be significantly weaker in the deacetalized copolyesters, which is in full agreement with the observation of two $T_{\mathrm{g}}$ 's for these cases.

\subsection{Hydrolytic degradation}

$\mathrm{PLLA}_{38^{-}}(\mathrm{PBiThx})_{19}-\mathrm{PLLA}_{38}$ and $\mathrm{PLLA}_{38}-(\mathrm{PBThOH})_{19}-\mathrm{PLLA}_{38}$ triblock copolyesters were incubated in citric acid buffer $(\mathrm{pH} 2.0)$, sodium phosphate buffer $(\mathrm{pH} 7.4)$ and sodium carbonate buffer $\left(\mathrm{pH} \mathrm{10)}\right.$ at $37{ }^{\circ} \mathrm{C}$ for 40 days, and the evolution of the degradation undergone by the copolyester was followed by monitoring the changes taking place in sample weight and molecular weight of the residue. According to what should be expected for aliphatic polyesters, a continuous decreasing in both parameters with time was observed for the two copolyesters as it is clearly demonstrated in Figure 6 . In general it was observed that degradation rate was higher at basic $\mathrm{pH}$, especially for the case of the PLLA $_{38^{-}}(\mathrm{PBThOH})_{19}$ PLLA $_{38}$ copolyester, which became disintegrated into a fine powder after the a few days of incubation. On the other hand, degradation differences at neutral $\mathrm{pH}$ were insignificant with values of both sample and molecular weights being decreasing with time in a similar manner for the two copolyesters. The GPC curves obtained at different degradation times for the two copolyesters under study under a selection of the conditions assayed are provided in the SI file as Figure S7. 

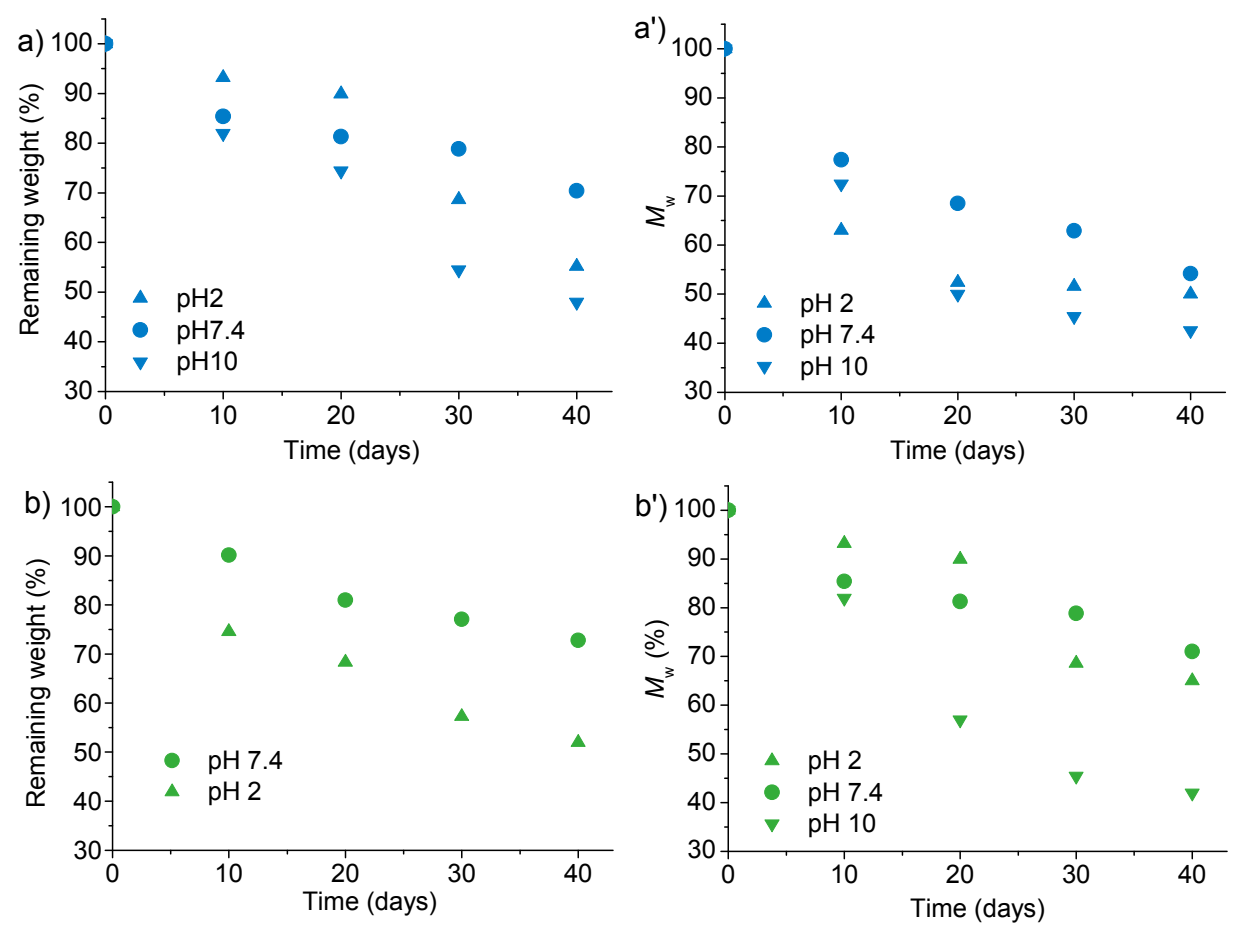

Figure 6. Evolution of the degradation process in $\mathrm{PLLA}_{38^{-}}(\mathrm{PBiThx})_{19}-\mathrm{PLLA}_{38}$ (a and a') and PLLA $\mathrm{A}_{38^{-}}$ $(\mathrm{PBThOH})_{19}-\mathrm{PLLA}_{38}$ (b and b') copolyesters along incubation time at different $\mathrm{pH}$. Remaining weight data for $\mathrm{pH} 10$ are missing in b) because the residue disintegrated after a few days of incubation.

To get insight into the degradation mechanism, the two copolyesters under study PLLA $_{38^{-}}(\mathrm{PBiThx})_{19}-\mathrm{PLLA}_{38}$ and PLLA $_{38^{-}}(\mathrm{PBThOH})_{19}-\mathrm{PLLA}_{38}$ were immersed in aqueous buffer at pH 2 and $\mathrm{pH} 10$, respectively, in NMR tubes at $37^{\circ} \mathrm{C}$, and ${ }^{1} \mathrm{H}$ NMR spectra were recorded from the supernatant after 40 days of incubation (Figure 7). As expected the spectra recorded for both copolyesters contain signals corresponding to lactic and tartaric acids, and 1,4-butanediol whereas acetone was found to be present also in the PLLA P $^{-}$ (PBiThx $)_{19}-$ PLLA $_{38}$ supernatant. On the other hand, the ${ }^{1} \mathrm{H}$ NMR of the residue left by PLLA $_{38}-(\mathrm{PBiThx})_{19}-\mathrm{PLLA}_{38}$ revealed that the content in BiThx units of this sample had decreased about $10 \%$-mole, i.e. about one half of these units was released to the incubation medium (Figure $\mathrm{S} 7$ in $\mathrm{SI}$ ). These results reveal that upon incubation the acetal group was split in some degree and they may be taken as demonstrative that hydrolysis of these triblock copolyesters preferably happens by splitting of the ester groups in which the tartaric units are directly implied. 
a)
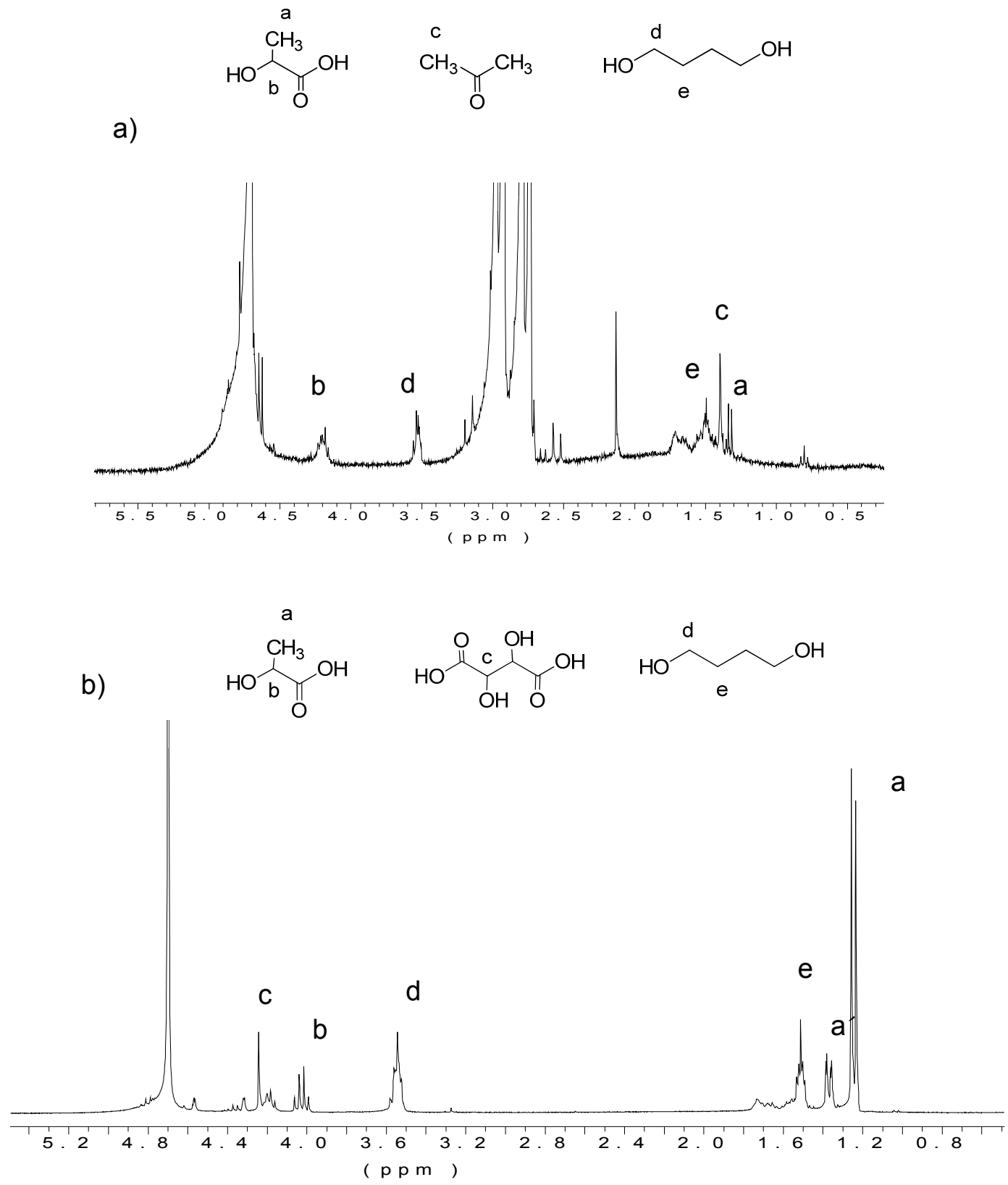

Figure 7. ${ }^{1} \mathrm{H}$ NMR spectra in $\mathrm{D}_{2} \mathrm{O}$ of the products released by $\mathrm{PLLA}_{38}-(\mathrm{PBiThx})_{19}-\mathrm{PLLA}_{38}$ (a) and $\mathrm{PLLA}_{38}-(\mathrm{PBThOH})_{19}-\mathrm{PLLA}_{38}$ (b) copolyesters to the aqueous medium after incubation for 40 days at $\mathrm{pH} 2$ and $\mathrm{pH} 10$, respectively.

\subsection{Nanoparticle formation}

Nanoparticles of PLLA $_{38}-(\mathrm{PBiThx})_{19}-\mathrm{PLLA}_{38}$ and $\mathrm{PLLA}_{38}-(\mathrm{PBThOH})_{19}-\mathrm{PLLA}_{38}$ were obtained by the solvent-replacement method by dialysis against water of the copolyester solutions in DMSO. The size distribution profiles of the nanoparticles obtained from the four copolyesters by DLS are compared in Figure 8, and illustrative SEM pictures are shown in 
Figure 9. The most characteristic parameters of these nanoparticles are collected in Table 3. Well-shaped spherical particles displaying average diameters in the $150-450 \mathrm{~nm}$ range with satisfactory dispersities were obtained. Interestingly the size of nanoparticles formed by copolyesters with free hydroxyl groups were up to two times greater than the size of nanoparticles formed by their protected analogues. According to the one-phase and twophase models put forward for PLLA $38^{-}(\mathrm{PBiThx})_{19^{-}} \mathrm{PLLA}_{38}$ and $\mathrm{PLLA}_{38^{-}}(\mathrm{PBThOH})_{19}-\mathrm{PLLA} \mathrm{A}_{38}$, respectively, the particles made from the latter are assumed to consist of a shell-core structure with the PLLA blocks filling the inner space and the hydroxylated PBThOH block preferently located on the surface. The space requirements for such biphasic arrangement together with the hydratation of the external hydroxylated phase could explain the greater size reached by the $\mathrm{PLLA}_{38}-(\mathrm{PBThOH})_{19}-\mathrm{PLLA}_{38}$ nanoparticles. On the other hand, the particle size was found to decrease in the two systems as the length of the PLLA block increased, which is a result according to that obtained with other related triblock copolyesters made of lactic and acetalized glucaric acids [23], and that could be rationalized taken into account the greater crystallinity or/and higher packing efficiency that is attained for longer PLLA blocks.

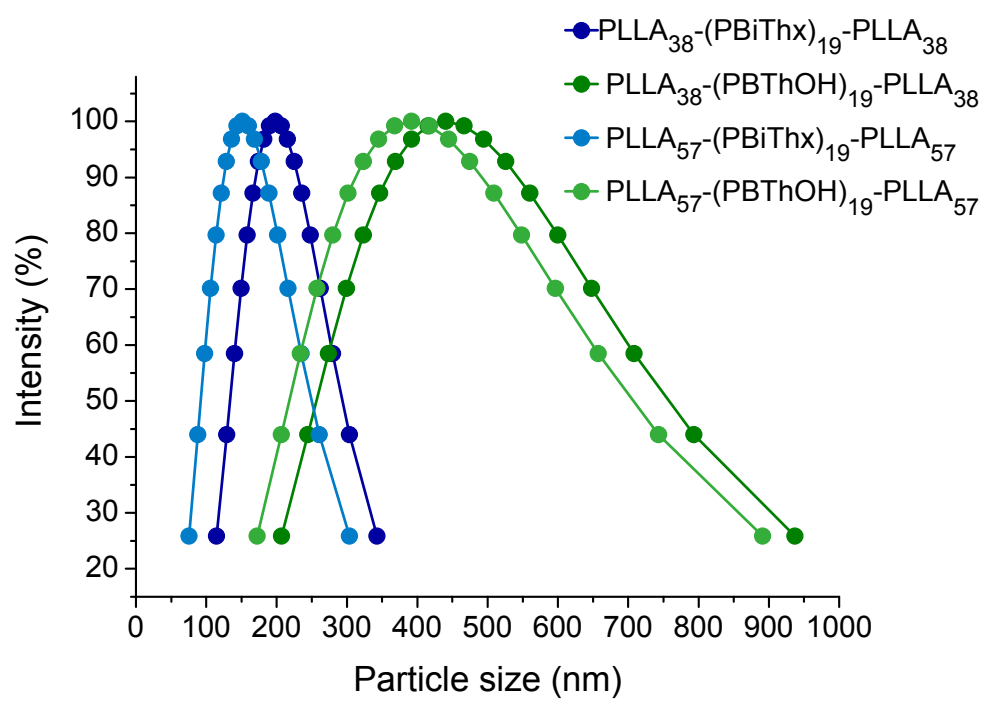

Figure 8. Size distribution profiles of nanoparticles made by triblock copolyesters.. 
Table 3. Nanoparticle properties.

\begin{tabular}{|c|c|c|c|c|}
\hline \multirow[t]{2}{*}{ Triblock copolyester } & \multicolumn{2}{|c|}{ Particle size $(\mathrm{nm})$} & \multirow[t]{2}{*}{$D$} & \multirow[t]{2}{*}{$\zeta$-potential $(\mathrm{mV})$} \\
\hline & DLS & SEM & & \\
\hline$\overline{\text { PLLA }_{38}-(\mathrm{PBiThx})_{19}-\mathrm{PLLA}_{38}}$ & $198 \pm 7$ & $260 \pm 20$ & 0.117 & -23.0 \\
\hline $\mathrm{PLLA}_{57}-(\mathrm{PBiThx})_{19}-\mathrm{PLLA}_{57}$ & $151 \pm 2$ & $172 \pm 20$ & 0.196 & -15.0 \\
\hline $\begin{array}{l}\text { PLLA }_{38}-(\mathrm{PBThOH})_{19}-\mathrm{PLLA}_{38} \\
\text { PLLA }_{57}-(\mathrm{PBThOH})_{19}-\mathrm{PLLA}_{57}\end{array}$ & $\begin{array}{l}440 \pm 29 \\
392 \pm 19 \\
\end{array}$ & $\begin{array}{l}438 \pm 26 \\
440 \pm 24 \\
\end{array}$ & $\begin{array}{l}0.234 \\
0.283 \\
\end{array}$ & $\begin{array}{l}-29.9 \\
-18.0 \\
\end{array}$ \\
\hline
\end{tabular}

Zeta-potential is an important tool for understanding the molecular arrangement in the nanoparticle surface and predicting its long term stability. The Zeta-potential of the four triblock copolyesters examined in this work was found to be negative with values ranging between -29 and $-15 \mathrm{mV}$. Such negative values are consistent with the presence of a high concentration of oxygen atoms on the particle surface such as it was described above. The higher negative Zeta-potential value displayed by the deacetalized copolyesters is according with what should be expected from the greater negative polarity of the free hydroxyl groups compared to the acetalized ones. On the other hand, the remarkable Zetapotential differences observed (about $10 \mathrm{mV}$ ) for the copolyesters with PLLA blocks of different length could be explained by assuming that part of the lactate units must be lodged in the particle surface. Obviously such interpenetration will be more extensive as the proportion of PLLA in the copolyester increases. At any case, the higher Zeta-potential negative value showed by these nanoparticles is a favorable feature for their stability since spontaneous aggregation will be hindered by mutual electrostatic repulsion. 

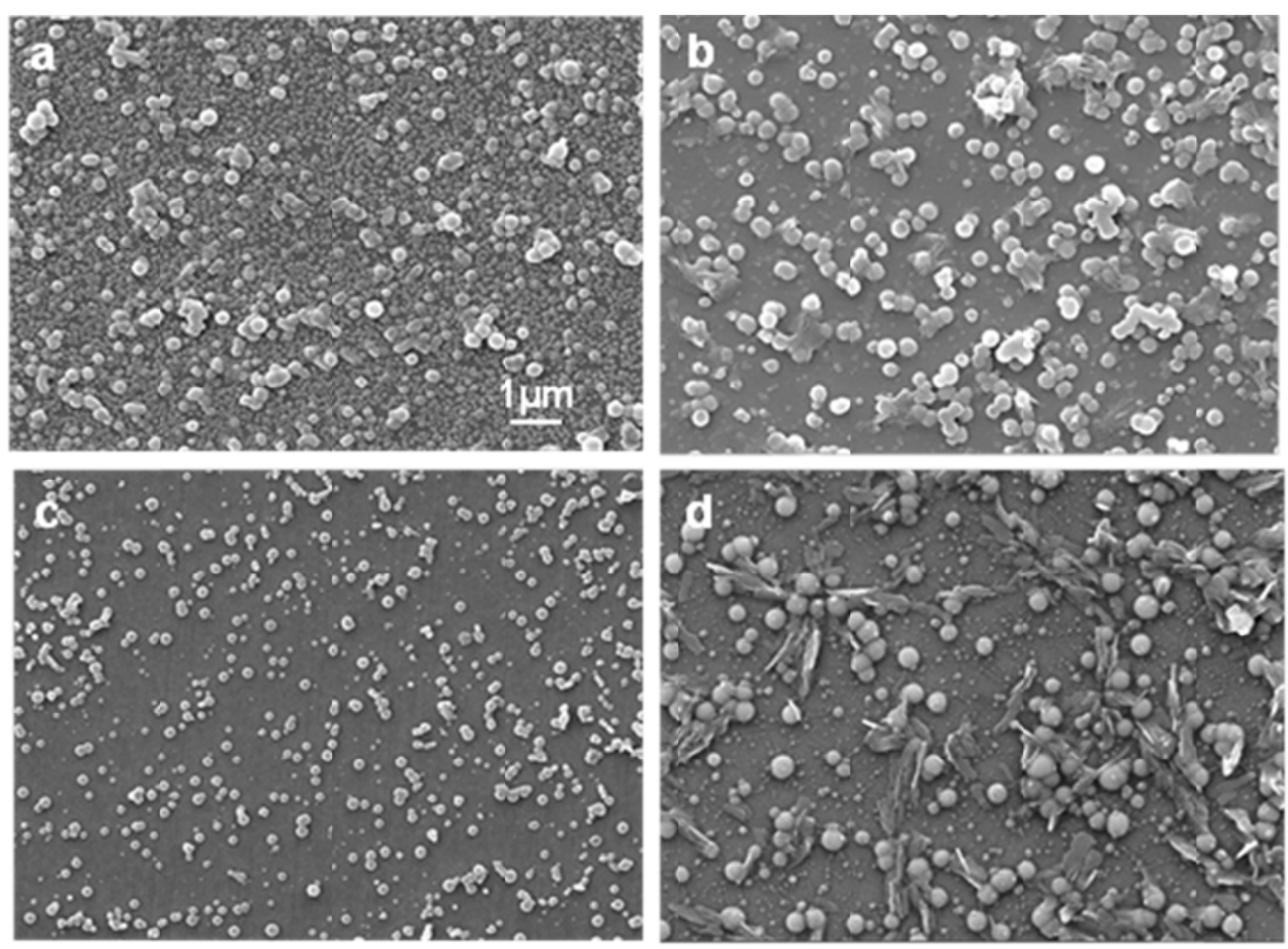

Figure 9. SEM images of nanoparticles made of $\mathrm{PLLA}_{38}-(\mathrm{PBiThx}){ }_{19}-\mathrm{PLLA}_{38}(\mathrm{a}), \mathrm{PLLA}_{38}-(\mathrm{PBThOH})_{19^{-}}$ $\mathrm{PLLA}_{38}(\mathrm{~b}), \mathrm{PLLA}_{57}-(\mathrm{PBiThx})_{19}-\mathrm{PLLA}_{57}$ (c) and PLLA $\mathrm{A}_{57}-(\mathrm{PBThOH})_{19}-\mathrm{PLLA}_{57}$ (d) triblock copolyesters.

Although no specific study on the stability of the nanoparticles has been performed in this work, the high relevance of this property deserves a brief comment relative to such aspect. In our recent paper on nanoparticles made of triblock copolyesters consisting of polylactide and acetalized poly(glucitol succinate) [23], which are polymers very close structurally to the protected ones studied in this work, it was shown that the stability of such nanoparticles suspended in aqueous buffers was highly depending on temperature. In fact, those nanoparticles maintained their physical integrity during storage at room temperature for five days but coalesced very fast when temperature increased above $37^{\circ} \mathrm{C}$. Given the similitude of the copolyesters used in the two works, a similar behavior could be reasonably expected for the present case, at least for nanoparticles made of protected copolyester.

\section{Conclusions}

Triblock copolyesters PLLA $-(P B i T h x)_{19}-$ PLLA $_{y}$ with two different PLLA block lengths, i.e. 38 and 57 units, were successfully synthesized via ROP of L-lactide using as initiator a telechelic hydroxyl-capped poly(butylene tartrate). In these copolyesters, the hydroxyl side 
groups of the tartrate unit are acetalized with acetone. At difference with methylidene acetals, these isopropylidene acetals were susceptible of controlled hydrolysis to generate the hydroxyl-functionalized copolyesters with a high amphiphilic character. All the triblock copolyesters showed a good thermal stability and were found to be semicrystalline. Interestingly, acetalized copolyesters showed only one $T_{\mathrm{g}}$ intermediate between those of PBiThx and PLLA blocks, while the deacetalized ones bearing free-hydroxyl groups showed two $T_{\mathrm{g}}$ 's indicating a sharper segregation of the two blocks. The four copolyesters were able to form structured nanoparticles at the nanoscale dimension with a noticeable negative Zeta-potential. The favorable structural features of these nanoparticles, their surface functionalization, and the sensitivity to hydrolysis under mild conditions displayed by the copolyesters used for their building, confer them an enormous potential for the design of drug delivery systems with targeting and responsive capacities.

\section{Acknowledgements}

This work received financial support from MICINN of Spain with Grants MAT2012-38044C03-03 and MAT2016-77345-C3-1-P and from AGAUR with grant 2009SGR1469. Thanks also to MECD of Spain for the Ph.D. grant awarded to Elena Zakharova.

\section{References}

[1] R. Gref, P. Couvreur, G. Barratt, E. Mysiakine, Surface-engineered nanoparticles for multiple ligand coupling. Biomaterials 24 (2003) 4529-4537.

[2] R. Mout, D.F. Moyano, S. Rana, V.M. Rotello, Surface functionalization of nanoparticles for nanomedicine, Chem. Soc. Rev. 41 (2012) 2539-2544.

[3] N.H. Abd Ellah, S.A. Abouelmagd, Surface functionalization of polymeric nanoparticles for tumor drug delivery: approaches and challenges, Exp. Opinion Drug Deliv. 14 (2017) 201-214.

[4] C.C. You, O.R. Miranda, B. Gider, P.S. Ghosh, I.B. Kim, B. Erdogan, S.A. Krovi, U.H. Bunz, V.M. Rotello, Detection and identification of properties using nanoparticle-fluorescent polymer "chemical nose" sensors, Nat. Nanotech. 2 (2007) 318-323.

[5] Y. Jiang, H. Zhao, Y. Lin, N. Zhu, Y. Ma, L. Mao, Colorimetric detection of glucose in rat brain using gold nanoparticles, Angew. Chem. Int. Ed. Engl. 49 (2010) 4800-4804.

[6] A. Bajaj, O.R. Miranda, I.B. Kim, R.L. Phillips, D.J. Jerry, U.H. Bunz, V.M. Rotello, Detection and differentiation of normal, cancerous, and metastatic cells using nanoparticle-polymer sensor arrays, Proc. Natl. Acad. Sci. U S A. 106 (2009) 10912-10916. 
[7] A. Bajaj, S. Rana, O.R. Miranda, J.C. Yawe, D.J. Jerry, U.H.F. Bunz, V.M. Rotello, Cell surfacebased differentiation of cell types and cancer states using a gold nanoparticle-GPF based sensing array, Chem. Sci. 1 (2010) 134-138.

[8] K. El-Boubbou, D.C. Zhu, C. Vasileiou, B. Borhan, D. Prosperi, W. Li, X. Huang, Magnetic glyconanoparticles: a tool to detect, differentiate and unlock the glycol-codes of cancer via magnetic resonance imaging, J. Am. Chem. Soc. 132 (2010) 4490-4499.

[9] E.C. Dreaden, M.A. Mackey, X. Huang, B. Kang, M.A. El-Sayed, Beating cancer in multiple ways using nanogold, Chem. Soc. Rev. 40 (2011) 3391-3404.

[10] H.J. Krause, A. Schwarz, P. Rohdewald, Polylactic acid nanoparticles, a colloidal drug delivery system for lipophilic drugs, Intern. J. Pharm. 27 (1985) 145-155.

[11] R.C. Mundargi, V.R. Babu, V. Rangaswamy, P. Patel, T.M. Aminabhavi, M. Tejraj, Nano/micro technologies for delivering macromolecular therapeutics using poly(D,L-lactide-co-glycolide) and its derivatives, J. Control. Release 125 (2008) 193-209.

[12] R. Dinarvand, N. Sepehri, S. Manoochehri, H. Rouhani, F. Atyabi, Polylactide-co-glycolide nanoparticles for controlled delivery of anticancer agents, Internat. J. Nanomed. 6 (2011) 877-895.

[13] S.Y. Lee, H.J. Cho, Amine-functionalized poly(lactic-co-glycolic acid) nanoparticles for improved cellular uptake and tumor penetration, Colloids Surf. B Biointerfaces. 148 (2016) 85-94.

[14] M. Leemhuis, C.F. Nostrum, J.A.W. Kruijtzer, Z.Y. Zhong, M.R. ten Breteler, P.J. Dijkstra, J. Feijen, W.E. Hennink, Functionalized poly(a-hydroxy acid)s via ring-opening polymerization: toward hydrophilic polyesters with pendant hydroxyl groups, Macromolecules 39 (2006) 3500-3508.

[15] M. Leemhuis, J.A.W. Kruijtzer, C.F. Nostrum, W.E. Hennink, In vitro hydrolytic degradation of hydroxyl-functionalized poly(a-hydroxy acid)s, Biomacromolecules 8 (2007) 2943-2949.

[16] P. Datta, J. Chatterjee, S. Dhara, Phosphate functionalized and lactic acid containing graft copolymer: synthesis and evaluation as biomaterial for bone tissue engineering applications $\mathrm{J}$. Biomater. Sci. Polym. Ed. 24 (2013) 696-713.

[17] J.K. Oh, Polylactide (PLA)-based amphiphilic block copolymers: synthesis, self-assembly, and biomedical applications, Soft Matter 7 (2011) 5096-5108.

[18] T.B.T. Nguyen, S. Li, A. Deratani, Reverse micelles prepared from amphiphilic polylactide-bpoly (ethylene glycol) block copolymers for controlled release of hydrophilic drugs, Intern. J. Pharm. 495 (2015) 154-161.

[19] A.C. Albertsson, I.K. Varma, Recent developments in ring opening polymerization of lactones for biomedical applications, Biomacromolecules 4 (2003) 1466-1486.

[20] M.A. Hillmyer, William B. Tolman, Aliphatic polyester block polymers: renewable, degradable, and sustainable, Acc. Chem. Res. 47 (2014) 2390-2396.

[21] E. Themistou, G. Battaglia, S.P. Armes, Facile synthesis of thiol-functionalized amphiphilic polylactide-methacrylic diblock copolymers, Polym. Chem. 5, (2014) 1405-1417.

[22] Z. Jing, X. Shi, G. Zhang, Synthesis and properties of biodegradable supramolecular polymers based on polylactide-block-poly( $\delta$-valerolactone)-block polylactide triblock copolymers, Polym. Int. 66 (2017) 1487-1497. 
[23] E. Zakharova, S. León, A. Alla, A. Martínez de Ilarduya, S. Muñoz-Guerra, Triblock copolyesters derived from lactic acid and glucose: Synthesis, nanoparticle formation and simulation, Eur. Polym. J. 92 (2017) 1-12.

[24] T. Lebar, E. Ibarboure, B. Gadenne, C. Alfos, H. Cramail, Fully bio-based poly(L-lactide)-bpoly(ricinoleic acid)-b-poly(L-lactide) triblock copolyesters: investigation of solid-state morphology and thermo-mechanical properties, Polym. Chem. 4 (2013) 3357-3369-

[25] Z. Beyazkilic, G. Lligadas, J.C. Ronda, M. Galia, V. Cádiz, Fully biobased triblock copolyesters from L-lactide and sulfur-containing castor oil derivatives: Preparation, oxidation and characterization, Polymer 68 (2015) 101-110.

[26] J.J. Bou, A. Rodríguez-Galán, S. Muñoz-Guerra, Optically active polyamides derived from Ltartaric acid, Macromolecules 26 (1993) 5664-5670.

[27] J.J. Bou, I. Iribarren, S. Muñoz-Guerra, Synthesis and properties of stereoregular polyamides derived from L-tartaric acid: poly[(2S,3S)-2,3-dimethoxybutylene alkanamide]s, Macromolecules 27 (1994) 5263-5270.

[28] I.A. Mathakiya, A.K. Rakshit, D.I. Bragadish, A.K. Shah, Novel biodegradable polyamides based on tartaric acid: [reparation and properties, Int. J. Polym. Mater. 53 (2004) 405-418.

[29] H. Kimura, T. Yoshinari, M. Takeishi, Synthesis and biodegradation of polyesters based on Omethylene tartaric acid, Polym. J. 31 (1999) 388-392.

[30] A. Alla, A. Rodríguez-Galán, A. Martínez de llarduya, S. Muñoz-Guerra, Degradable poly(ester amide)s based on L-tartaric acid, Polymer 38 (1997) 4935-4944.

[31] I. Villuendas, J.I. Iribarren, S. Muñoz-Guerra, Poly(esteramide)s derived from L-tartaric acid and amino alcohols. 1. Regic polymers, Macromolecules 32 (1999) 8015-8023.

[32] M. Acemoglu, S. Bantle, T. Mindt, F. Nimmerfall, Novel bioerodible poly(hydroxyalkylene carbonates)s: a versatile class of polymers for medical and pharmaceutical applications, Macromolecules 28 (1995) 3030-3037.

[33] M. Yokoe, K. Aoi, M. Okada, Biodegradable polymers based on renewable resources. Synthesis and degradation behavior of polycarbonates based on 1,4:3,6-dianhydrohexitols and tartaric acid derivatives with pendant functional groups, J. Polym. Sci., Part A: Polym. Chem. 43 (2005) 39093919.

[34] S. Dhamaniya, J. Jacob, Synthesis and characterization of copolyesters based on tartaric acid derivatives, Polym. Bull. 68 (2012) 1287-1304.

[35] J. Wang, R.M. Wolf, J.W. Caldwell, P.A. Kollman, D.A.J. Case, Development and testing of a general amber force field. Comput. Chem. 25 (2004) 1157-1174.

[36] Y. Shao et al. Advances in molecular quantum chemistry contained in the Q-Chem 4 program packkage, Mol. Phys. 113 (2015) 184-215.

[37] L. Martínez, R. Andrade, E.G. Birgin, J.M.J. Martínez, PACKMOL: A package for building initial configurations for molecular dynamics simulations, Comput. Chem. 30 (2009) 2157-2164.

[38] S.J. Plimpton, Fast parallel algorithms for short-range molecular-dynamics, Comp. Phys. 117 (1995) 1-19. 
[39] E. Zakharova, C. Lavilla, A. Alla, A. Martínez de llarduya, S. Muñoz-Guerra, Modification of properties of poly(butylene succinate) by copolymerization with tartaric acid-based monomers, Eur. Polym. J. 61 (2014) 263-273. 